\title{
Caracterização morfológica de frutos, sementes e fases da germinação de Pachira aquatica Aubl. (Bombacaceae)
}

\section{Morphological characterization of fruits, seeds and phases of germination Pachira aquatica Aubl. (Bombacaceae)}

\author{
Kelina Bernardo Silva ${ }^{1 *}$; Edna Ursulino Alves²; \\ Valderez Pontes Matos ${ }^{3}$; Riselane de Lucena Alcântara Bruno²
}

\begin{abstract}
Resumo
A mongubeira (Parchira aquatica Aubl.) é uma frutífera utilizada na arborização urbana de muitas cidades no interior do país e pouco frequente em seu habitat natural, nas matas periodicamente inundáveis do litoral do Pará e Maranhão. Este trabalho teve como objetivo descrever e ilustrar as características morfológicas externas e internas de frutos e sementes, bem como as fases do processo de germinação de $P$. aquatica. Para a descrição dos frutos foram observados detalhes externos e internos do pericarpo, referentes à textura, consistência, pilosidade, brilho, forma, número de sementes por fruto e deiscência. Para a morfologia de sementes foram observadas as seguintes características externas: dimensões, cor, textura, consistência, forma, posição do hilo e da micrópila. Para as características internas, verificou-se a presença ou ausência de endosperma e tipo de embrião. Os frutos de $P$. aquatica são cápsulas semilenhosas, deiscentes, formato geralmente ovalado, alguns são arqueados e com fendas longitudinais no pericarpo, sendo constituídos por cinco septos, polispérmicos e coloração castanho-escura. As sementes variam de reniformes a angulosas, possuem grande quantidade de endosperma e estão inseridas no eixo central do fruto. A germinação é do tipo epígea fanerocotiledonar, com início no oitavo dia e podendo ser encerrada no $15^{\circ}$ dia após semeadura.
\end{abstract}

Palavras-chave: Monguba, espécie florestal, morfologia vegetal

\begin{abstract}
The mongubeira (Pachira aquatica Aubl) is a fruit used in urban forestry in many cities within the country and infrequent in their natural habitat in the forests periodically flooded the coast of Pará and Maranhão. This study aimed to describe and illustrate the external and internal morphological characteristics of fruits and seeds, as well as the stages of germination of $P$. aquatica. For a description of the fruits were observed internal and external details of the pericarp, related to texture, texture, hairiness, brightness, shape, number of seeds per fruit and dehiscence. For seed morphology were observed following external dimensions, color, texture, consistency, shape, position of hilum and micropyle. For the internal characteristics, there was the presence or absence of endosperm and embryo type. The fruits of $P$. aquatica capsules are semi-woody, dehiscent, generally oval shape, some are curved and longitudinal cracks in the pericarp, is made up of five septa, polispermic and stained dark brown. The seeds vary from angular to reniform, have a large amount of endosperm and are inserted into the central axis of the fruit. Germination is epigeal type phanerocotylar, starting on the eighth day and can be terminated on the 15 th day after sowing.
\end{abstract}

Key words: Monguba, forest species, plant morphology

${ }^{1}$ Prof $^{a}$ Adjunta do Dept ${ }^{\circ}$. de Agrárias e Exatas, Universidade Federal de Paraíba, CCHA, Catolé do Rocha, PB. E-mail: kelinabernardo@yahoo.com.br

2 Profs. Adjuntos do Dept ${ }^{\circ}$. de Fitotecnia, CCA/UFPB, Areia, PR. E-mail: ednaursulino@cca.ufpb.br; lane@cca.ufpb.br

3 Profa. Adjunta, Universidade Federal Rural de Pernambuco, UFRPE, Recife, PE. E-mail: vpmatos@hotmail.com

* Autor para correspondência 


\section{Introdução}

A mongubeira (Pachira aquatica Aubl.) é uma frutífera utilizada na arborização urbana de várias cidades do interior do país e, pouco freqüente em seu habitat natural, que são as matas periodicamente inundáveis do litoral do Pará e Maranhão. É uma árvore perenifólia de copa densa, medindo de 6-14 m de altura. Suas castanhas podem ser consumidas in natura, porém geralmente são torradas (LORENZI et al., 2006).

Para muitos autores a dificuldade de se estudar a estrutura, a fenologia e o comportamento de uma espécie, dentro de uma comunidade vegetal é a sua identificação. Neste sentido, Roderjan (1983) e Pinheiro (1986) mencionaram três caminhos: a taxonomia botânica, que utiliza os órgãos reprodutivos das plantas; a anatomia da madeira, que faz uso dos elementos constitutivos do lenho e a dendrologia, que se baseia nas características macroscópicas dos órgãos vegetativos. Além destes, conforme enfatizou Oliveira (1993), a morfologia de plantas também tem merecido atenção, quer seja como parte de estudos morfo-anatômicos para ampliar o conhecimento sobre determinada espécie ou agrupamento sistemático de plantas, ou para facilitar a identificação de plantas de uma região, dentro de um enfoque ecológico.

Entre os diversos procedimentos adotados para a caracterização de uma espécie vegetal, destacase a diagnose morfológica. Portanto, o estudo da morfologia de frutos, sementes e plântulas nos estágios iniciais de desenvolvimento contribui para melhorar o conhecimento do processo reprodutivo das espécies vegetais e dar subsídio para a produção de mudas, além de ser fundamental à compreensão do processo de estabelecimento da planta em condições naturais (GUERRA; MEDEIROS FILHO; GALHÃO, 2006).

O estudo do tamanho, forma e tipo de deiscência dos frutos são caracteres imprescindíveis para a classificação, de forma que os estudos morfológicos de frutos contribuem para a identificação das espécies, bem como sua distribuição geográfica e interações com a fauna (BARROSO et al., 2004). Esse tipo de informação pode servir tanto para melhorar a conservação da fauna e da flora, principalmente das espécies que se encontram em via de extinção, quanto contribuir com estudos de sucessão ecológica e regeneração dos ecossistemas florestais (BELTRATI, 1995).

Quanto aos frutos, a descrição e a classificação constituem um item complexo na área da morfologia vegetal, pois, tanto as descrições como as conceituações são em geral restritas e imperfeitas (VIDAL, 1978). A caracterização morfológica do fruto e semente é necessária devido à importância dessa estrutura na identificação botânica das espécies e no estudo do meio de dispersão e regeneração, além do seu papel biológico e utilização na alimentação humana e animal (ARAÚJO et al., 2004; MARCOS FILHO, 2005). As sementes apesar de serem formadas basicamente por embrião, tecidos de reserva e envoltório, na natureza, diversos fatores contribuem para que haja desenvolvimento diferenciado dos seus componentes, variando entre espécies e até dentro da própria espécie, através da cor, forma e tamanho (ABUD et al., 2010a).

Além disso, a caracterização morfológica das sementes permite a obtenção de informações sobre a germinação, bem como a identificação de dormência, como a ocasionada por tegumento impermeável, que impossibilita a entrada de gases, ou mesmo a dormência causada pela imaturidade do embrião (CASTELLANI et al., 2008).

Em relação ao estudo dos aspectos morfológicos da germinação, este contribui para a propagação das espécies, pois aborda a classificação da germinação em relação à posição dos cotilédones e auxilia na interpretação e padronização dos testes de germinação, bem como permite a identificação das espécies em campo. Além disso, o conhecimento da germinação, envolvendo os aspectos morfológicos é importante para estudos taxonômicos, ecológicos e agronômicos (FERREIRA et al., 2001). 
Nesse sentido, esses dados têm merecido atenção há algum tempo, quer seja como parte de estudos morfo-anatômicos, objetivando ampliar o conhecimento de determinada espécie ou grupamento sistemático de plantas, quer visando o reconhecimento e identificação de plântulas de certa região, dentro de um enfoque ecológico (OLIVEIRA, 1993).

Estudos que visam o conhecimento da morfologia de frutos, sementes e plântulas de espécies arbóreas ainda são escassos na literatura referencial, tendo como exemplos trabalhos com várias famílias botânicas, a exemplo da Apocynaceae com as espécies Janaguba - Himatanthus drasticus (Mart.) Plumel. (AMARO et al., 2006) e sucuuba - Himatanthus sucuuba (Spruce) Wood. (FERREIRA; PIEDADE; BONATES, 2006), Burseraceae com breu - Protium Burm. f. (MELO; MACEDO; DALY, 2007), Papilionoideae com mulungu - Erythrina velutina Willd (SILVA et al., 2008), orelha-de-macaco - Enterolobium schomburgkii Benth. (RAMOS; FERRAZ, 2008), pau-cigarra - Senna multijuga var. lindleyana (Gardner) H. S. Irwin \& Barneby (AMORIM et al., 2008) e guiso-de-cascavel - Crotalaria lanceolata E. Mey. (ANDRADE et al., 2008), Fabaceae com mucuna preta - Mucuna aterrima Piper \& Tracy (ABUD; REIS.; TEÓFILO, 2009), Cactaceae com facheiro - Pilosocereus pachycladus Ritter. (ABUD et al., 2010b), Euphorbiaceae com branquilho Sebastiania commersoniana (Baillon) L. B. Smith \& R. J. Downs (COSMO et al., 2010).

Os estudos morfológicos de frutos, sementes e plântulas, apesar de serem variados e dispersos fornecem valiosas informações que permitem a identificação de muitas espécies em fases juvenis. Tal conhecimento é imprescindível quando se pretende compreender o ciclo biológico e a regeneração natural das espécies (OLIVEIRA, 1993). Do mesmo modo, estes estudos podem ser empregados para outros fins como: análise em laboratório, identificação e diferenciação de espécies em viveiros e reconhecimento da planta no campo, havendo, portanto, a necessidade de estímulos a esses estudos básicos.

A espécie Pachira aquatica foi escolhida em função da sua ocorrência na região, importância social e ecológica, disponibilidade de frutos e da ausência de informações com relação aos aspectos morfológicos. Assim, o trabalho objetivou descrever as características morfológicas externas e interna de frutos e sementes, bem como as fases do processo germinação e de plântula de Parquira aquatica por meio de ilustrações.

\section{Material e Métodos}

O presente trabalho foi realizado nos Laboratórios de Análise de Sementes (LAS) e de Botânica do Departamento de Fitotecnia da Universidade Federal da Paraíba, em Areia-PB. Os frutos foram coletados com auxílio de um podão de cinco árvores matrizes de diferentes fragmentos florestais, no município de Areia-PB. Em seguida, o material coletado foi transportado para o LAS, onde as sementes mal formadas e com injúrias foram eliminadas manualmente.

O município de Areia-PB está situado a $575 \mathrm{~m}$

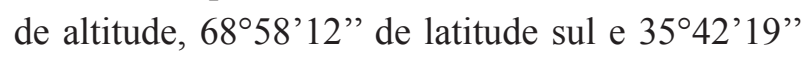
de longitude oeste de Greenwich. O clima da região, segundo classificação de Köppen, é do tipo As', que se caracteriza por ser quente $\left(25^{\circ} \mathrm{C}\right)$ e úmido $(85 \%)$, com chuvas de outono-inverno (1.200 mm anuais) e período de estiagem de 5 a 6 meses, com solos moderadamente ácidos (GONDIM; FERNANDES, 1980).

Para descrição morfológica de frutos e sementes utilizaram-se 100 unidades, escolhidas aleatoriamente. Foram descritas e ilustradas as características morfológicas externas e internas de frutos e sementes, considerando os seguintes aspectos para caracterização do fruto: formato, cor, dimensões (comprimento, largura e espessura) e número de sementes por fruto. Para descrição das sementes foram feitos cortes transversais e 
longitudinais com lâminas; sendo analisadas as seguintes variáveis: externas - coloração, dimensões (comprimento, largura e espessura), textura e consistência dos tegumentos, forma e dimensões (comprimento e largura) do hilo; internas - tipo de embrião (cotilédones, eixo hipocótilo-radícula e plúmula), forma, tamanho, localização e presença ou ausência de endosperma.

As dimensões (comprimento, largura e espessura) de frutos e sementes foram obtidas com paquímetro de $0,05 \mathrm{~mm}$ de precisão. As ilustrações foram feitas a olho nu ou com auxílio de lupa de mesa, em escala 1:1 e quando necessário foram ampliadas. $\mathrm{O}$ método e os termos empregados foram baseados nos trabalhos de Vidal e Vidal (2000), Barroso et al. (2004), Silva et al. (2008) e Queiroz e Bianco (2009).

Para observar a estrutura dos tegumentos das sementes, as mesmas foram colocadas em água fervente por 5 minutos, facilitando a retirada.

Para acompanhamento do processo de germinação, 100 sementes foram semeadas em bandejas de polietileno com dimensões de 41 x 36 x 7,6 cm de comprimento, largura e profundidade, respectivamente, sobre o substrato vermiculita umedecido com água destilada quando necessário. As bandejas foram mantidas em casa de vegetação e as etapas da germinação foram observadas diariamente e ilustradas a olho nu e com auxílio de lupa de mesa. A germinação foi considerada desde o intumescimento da semente até a emissão dos protófilos de primeira ordem.

A plântula estabelecida foi considerada quando os protófilos de primeira ordem já estavam totalmente expandidos. Nesta fase, os caracteres descritos e ilustrados foram os mesmos sugeridos por Roderjan (1983): raiz (principal e secundárias), colo, hipocótilo, cotilédones, epicótilo e protófilos de primeira ordem. Para as medições das plântulas utilizou-se régua graduada em centímetros. As ilustrações foram feitas a olho nu ou com auxílio de lupa de mesa.

O material utilizado nos estudos morfológicos foi conservado em álcool etílico a $70 \%$ e as ilustrações foram feitas manualmente de material bem desenvolvido e representativo de cada fase.

\section{Resultados e Discussão}

\section{Morfologia do fruto}

O fruto é do tipo cápsula septicida, deiscente, semi-lenhoso, polispérmico e de coloração castanhoescura, epicarpo glabro e sem brilho; mesocarpo de consistência fibrosa, cujo formato é geralmente ovalado, alguns são arqueados e com fendas longitudinais no pericarpo, sendo constituído por cinco septos com deiscência longitudinal (Figura 1A). No fruto há restos de pedúnculo persistentes e o endocarpo, que cobre as sementes como um todo, tem consistência esponjosa, coloração esbranquiçada e encontra-se geralmente localizado na parte central de cada septo, cuja base é constituída por pêlos curtos e translúcidos (Figura 1B). Os frutos têm, em média, 123,15 mm de comprimento, $81,94 \mathrm{~mm}$ de diâmetro e peso de 317 g. O número médio de sementes encontradas por fruto foi de 8,58, com número máximo 18 e mínimo 2 sementes (Tabela 1).

Tabela 1. Dimensões e peso dos frutos de Parchira aquatica Aulbl.

\begin{tabular}{lccccc}
\hline Dimensões (mm) & Média & Máximo & Mínimo & Desvio Padrão & CV (\%) \\
\hline Comprimento & 123,15 & 146,56 & 93,5 & 11,17 & 9,07 \\
Diâmetro & 81,94 & 96,62 & 7,13 & 5,84 & 7,13 \\
\hline Peso (g) & 317,02 & 479,7 & 139,5 & 73,83 & 23,29 \\
\hline
\end{tabular}

Fonte: Elaboração dos autores. 
Figura 1. Fruto de Parchira aquatica Aulbl. (A) vista frontal e (B) fruto cortado longitudinalmente. Legenda: sesementes; pr-pericarpo; ed- endocarpo; me-mesocarpo.
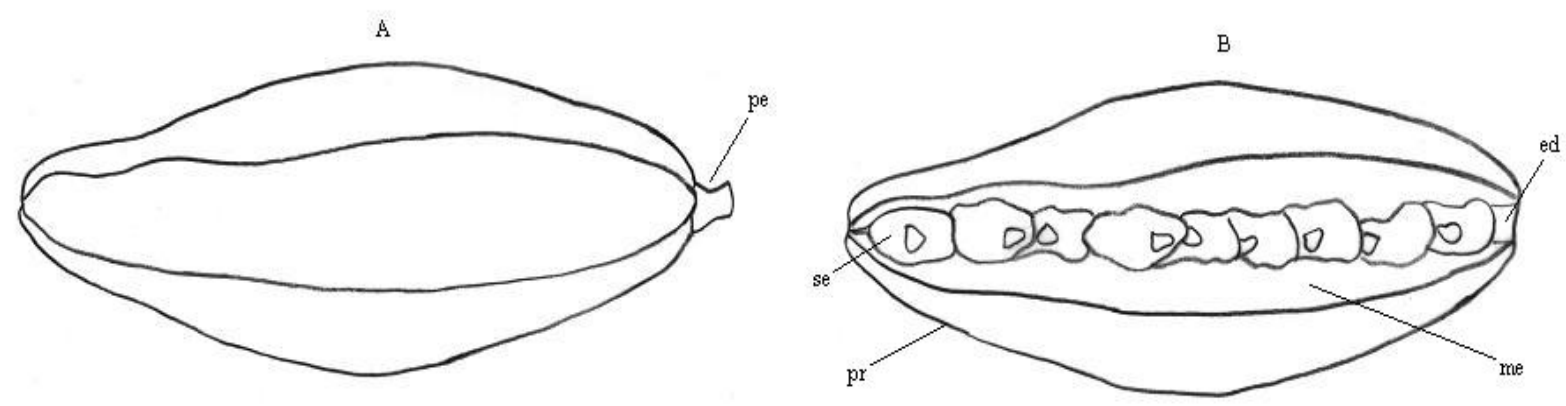

Fonte: Elaboração dos autores.

\section{Morfologia da semente}

As sementes são estenospérmicas, com formato variando de reniforme a angulosa (Figura 2A-B), as quais estão inseridas no eixo central do fruto. A coloração da testa é castanho-clara, com estrias reticuladas e escuras; consistência coreácea; tegma colado à face interna da testa, de coloração branca e espessura fina; consistência papirácea ou cartáceo. As sementes são parcialmente recobertas por um tecido esponjoso, de coloração esbranquiçada, provavelmente arilo. Hilo de formato codiforme a arredondado, com resquícios de tecido esponjoso. O embrião é invaginado, sulcado, dobrado, crasso, envolvendo totalmente o eixo hipocotilar, com endosperma hialino e gelatinoso (Figura 2C, D).
Os cotilédones são do tipo crassifólio, desiguais no tamanho e dobrados sobre o eixo hipocótilo-radícula, ou seja, os cotilédones são diferenciados, onde um é bem desenvolvido, carnoso, de formato codiforme e levemente sulcado e o outro é menor, apresentando o mesmo formato, carnoso e com estrias verticais (Figura 2E). Eixo hipocotilar de coloração semelhante aos cotilédones, cilíndrico, geralmente arqueado, com radícula punctiforme; plúmula rudimentar; micrópila inconspícua. As sementes têm, em média, comprimento, largura e espessura de 25,$16 ; 37,81$ e $25,45 \mathrm{~mm}$, respectivamente, com peso médio de $12,49 \mathrm{~g}$ (Tabela 2), enquanto o hilo tem comprimento e largura médios de 8,72 e 6,95 $\mathrm{mm}$, respectivamente (Tabela 3 ).

Tabela 2. Dimensões e peso da semente de Parchira aquatica Aulbl.

\begin{tabular}{lccccc}
\hline Dimensões (mm) & Média & Máximo & Mínimo & Desvio Padrão & CV (\%) \\
\hline Comprimento & 25,16 & 31,18 & 19,91 & 2,18 & 8,66 \\
Largura & 37,81 & 49,18 & 27,43 & 5,41 & 14,32 \\
Espessura & 25,45 & 32,39 & 14,4 & 2,70 & 10,61 \\
\hline Peso (g) & 12,49 & 17,6 & 6,5 & 2,17 & 17,40 \\
\hline
\end{tabular}

Fonte: Elaboração dos autores.

Tabela 3. Dimensões do hilo da semente de Parchira aquatica Aulbl.

\begin{tabular}{lccccc}
\hline Dimensões (mm) & Média & Máximo & Mínimo & Desvio Padrão & CV (\%) \\
\hline Comprimento & 8,72 & 12,27 & 4,46 & 1,83 & 21,04 \\
Largura & 6,95 & 12,36 & 3,27 & 1,83 & 26,39 \\
\hline
\end{tabular}

Fonte: Elaboração dos autores. 
Figura 2. Semente de Parquira aquatica Aulbl. A: Semente em vista frontal; B: Semente em vista lateral e C: Embrião. Legenda: tg-tegumentos, mi-micrópila; hi-hilo.
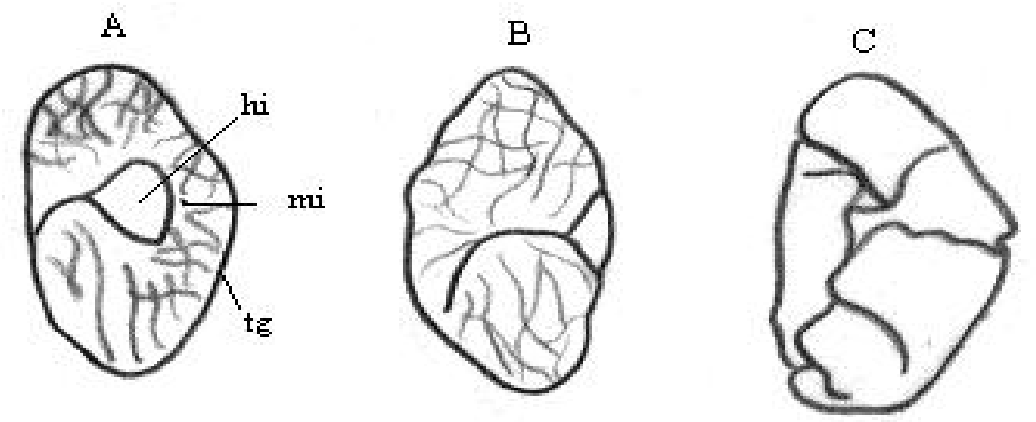

Fonte: Elaboração dos autores.

\section{Morfologia da germinação}

A germinação da semente de Parquira aquatica é epígea, do tipo fanerocotiledonar. O processo de germinação se inicia pelo surgimento da raiz, que rompe os tegumentos próximo à região hilar, oito dias após a semeadura, nessa fase tem $2 \mathrm{~cm}$ de comprimento (Figura 3A). A raíz primária é do tipo axial, esta desenvolve-se rapidamente, sendo inicialmente curta e cônica, vigorosa, de coloração perolada e glabra. À medida que ocorre seu alongamento, a coifa se diferencia e afunila, possuindo coloração amarelada. Nesta fase observa-se a presença de pêlos, curtos e translúcidos (Figura 3B). As raízes secundárias surgem simultaneamente com o desprendimento dos tegumentos, apresentando-se muito delgadas e com poucas ramificações, irregularmente distribuídas ao longo da raiz primária. Aos 10 dias de semeadura, o hipocótilo e a raiz estão alongados, medindo, aproximadamente, $13,4 \mathrm{~cm}$ de comprimento. Hipocótilo epígeo, cilíndrico, de coloração esverdeada, que aos 16 dias de semeadura atinge $16,6 \mathrm{~cm}$ de comprimento, elevando os cotilédones, que são persistentes. Aos 18 dias de semeadura, os cotilédones verdes, crassos e dobrados vão se expandindo até se abrirem totalmente, surgindo entre eles a gema apical, de coloração verde, nesta fase a plântula tem 20,5 cm de comprimento (Figura $3 \mathrm{C}$ ). Após esse período, a plântula já possui o epicótilo, hipocótilo, raiz e os protófilos, medindo 29,8 cm (Figura 3D). Seu sistema radicular é do tipo pivotante, com raiz principal cilíndrica, sublenhosa, tornando-se delgada na região apical, sinuosa e de coloração castanha; raízes secundárias curtas, cônicas, irregularmente distribuídas; coleto não visível. Hipocótilo longo, sub-herbáceo, cilíndrico, e de coloração verde. Cotilédones crassos, carnosos, persistentes e de coloração verde-escuro. Epicótilo longo, fino, reto e liso, com a mesma coloração do hipocótilo e tornando-se ereto à medida que se erguem os protófilos. Os protófilos de primeira ordem são verde-escuro, trifoliolados, peciolados, ápice acuminado, base aguda com bordas lisas. Epicótilo longo, em relação ao hipocótilo, variando entre 8,3 a 10,5 cm de comprimento, herbáceo, de coloração verde, cilíndrico, levemente canaliculado (Figura 3D).

A descrição morfológica dos frutos, sementes, germinação e plântula neste estudo exibem características peculiares da espécie que podem facilitar o seu reconhecimento e identificação em laboratório ou campo. 
Figura 3. Morfologia da germinação de sementes de Parquira aquatica Aulbl. A: Protrusão da raiz; B: Raiz primária com pêlos; C: Cotilédones expandidos e presença de raízes secundárias e D: plântula. Legenda: rz - raiz; tg tegumentos; $\mathrm{p}$ - pêlos radiculares; rp - raiz principal; rs - raiz secundária; hp - hipocótilo; co-coleto; c - cotilédones; pr - protófilos de $1^{\mathrm{a}}$ ordem; ep - epicótilo.
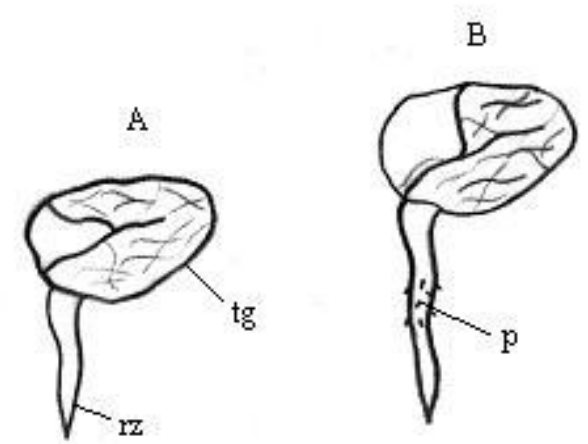
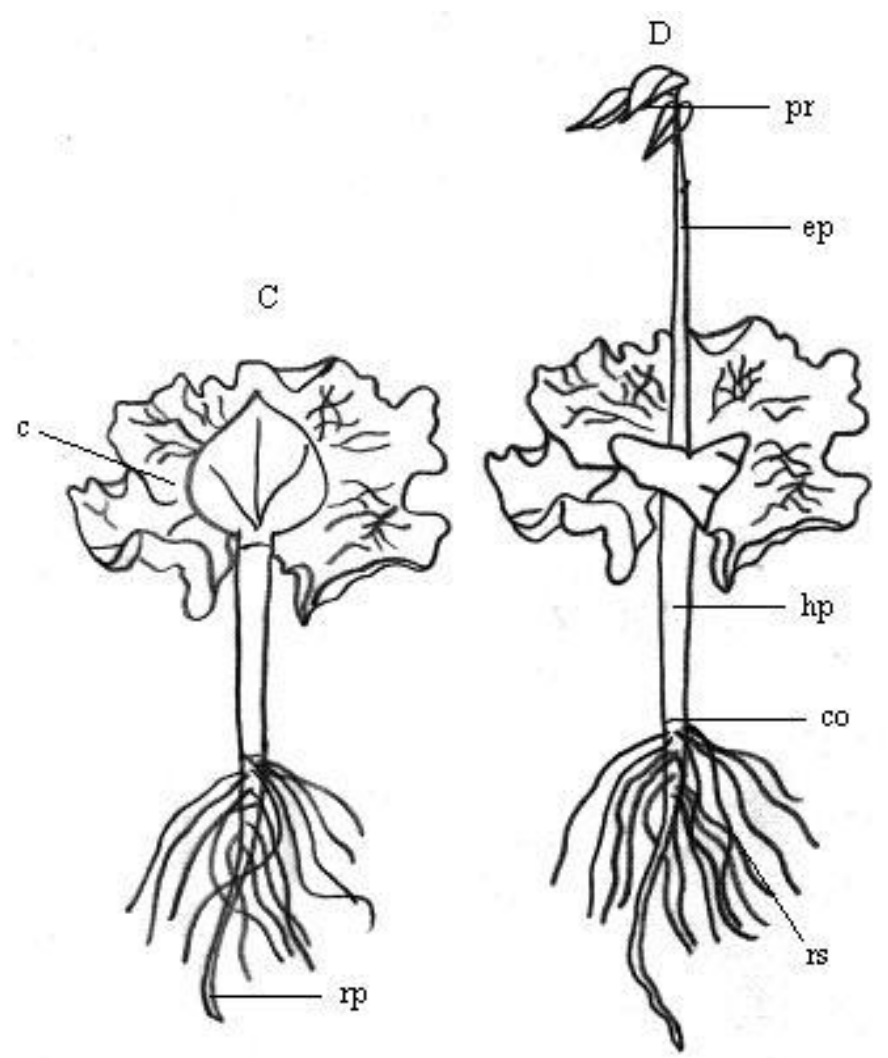

Fonte: Elaboração dos autores.

\section{Conclusões}

Os frutos de Parquira aquatica Aulbl. são do tipo cápsula loculicidas deiscentes e polispérmicos, de coloração castanha-escura e opaca;

As sementes variam de reniformes a angulosas, possui embrião do tipo invaginado, sulcado, dobrado, crasso envolvendo totalmente o eixo hipocotilar, com endosperma hialino e gelatinoso;

A germinação é do tipo epígea fanerocotiledonar com início ocorrendo aproximadamente no oitavo dia e termino no $15^{\circ}$ dia após a semeadura.

\section{Referências}

ABUD, H. F.; GONÇALVES, N. R.; REIS, R. G. E.; GALLÃO, M. I.; INNECCO, R. Morfologia de sementes e plântulas de cártamos. Revista Ciência Agronômica, Fortaleza, v. 41, n. 2, p. 259-265, 2010a.

ABUD, H. F.; GONÇALVES, N. R.; REIS, R. G. E.; PEREIRA, D. S.; BEZERRA. Germinação e expressão morfológica de frutos, sementes e plântulas de Pilosocereus pachycladus Ritter. Revista Ciência Agronômica, Fortaleza, v. 41, n. 3, p. 468-474, 2010 b.

ABUD, H. F.; REIS, R. G. E.; TEÓFILO, E. M. Caracterização morfológica de frutos, sementes, plântulas e germinação de Mucuna aterrima Piper \& Tracy. Revista Ciência Agronômica, Fortaleza, v. 40, n. 4, p. 563-569, 2009. 
AMARO, M. S.; MEDEIROS FILHO, S.; GUIMARÃES, R. M.; TEÓFILO, E. M. Morfologia de frutos, sementes e de plântulas de janaguba (Himatanthus drasticus (Mart.) Plumel. - Apocynaceae). Revista Brasileira de Sementes, Pelotas, v. 28, n. 1, p. 63-71, 2006.

AMORIM, I. L.; DAVIDE, A. C.; FERREIRA, R. A.; CHAVES, M. M. F. Morfologia de frutos, sementes, plântulas e mudas de Senna multijuga var. lindleyana (Gardner) H. S. Irwin \& Barneby-Leguminosae Caesalpinioideae. Revista Brasileira de Botânica, São Paulo, v. 31, n. 3, p. 507-516, 2008.

ANDRADE, D. A. V.; ORTOLANI, F. A.; MORO, J. R.; MORO, F. V. Aspectos morfológicos de frutos e sementes e caracterização citogenética de Crotalaria lanceolata E. Mey. (Papilionoideae - Fabaceae). Acta Botânica Brasílica, São Paulo, v. 22, n. 3, p. 621-625, 2008.

ARAÚJO, E. C.; MENDONÇA, A. V. R.; BARROSO, D. G.; LAMÔNICA, K. R.; SILVA, R. F. Caracterização morfológica de frutos, sementes e plântulas de Sesbania virgata (Cav.) Pers. Revista Brasileira de Sementes, Pelotas, v. 26, n. 1, p. 104-109, 2004.

BARROSO, G. M.; MORIM, M. P.; PEIXOTO, A. L.; ICHASO, C. L. F. Frutos e sementes: morfologia aplicada à sistemática de dicotiledôneas. Viçosa: UFV, 2004. $443 \mathrm{p}$.

BELTRATI, C. M. Morfologia e anatomia de sementes. Rio Claro: UNESP, 1995. 108 p.

CASTELLANI, E. D.; DAMIÃO FILHO, C. F.; AGUIAR, I. B.; PAULA, R. C. Morfologia de frutos e sementes de espécies arbóreas do gênero Solanum L. Revista Brasileira de Sementes, Londrina, v. 30, n. 1, p. 102-113, 2008.

COSMO, N. L.; NOGUEIRA, A. C.; LIMA, J. G.; KUNIYOSHI, Y. S. Morfologia de fruto, semente e plântula de Sebastiania commersoniana, Euphorbiaceae. Floresta, Curitiba, v. 40, n. 2, p. 419-428, 2010.

FERREIRA, C. S.; PIEDADE, M. T. F.; BONATES, L. C. Germinação de sementes e sobrevivência de plântulas de Himatanthus sucuuba (Spruce) Wood. em resposta ao alagamento, nas várzeas da Amazônia Central. Acta Amazonica, Manaus, v. 36, n. 4, p. 413-418, 2006.

FERREIRA, R. A.; GUIMARÃES, M. G. G. C.; PINHO, E. V. R.; TONETTI, O. A. O. Morfologia de sementes e plântulas e avaliação da viabilidade da semente de sucupira-branca (Pterodon pubescens Benth. Fabaceae) pelo teste de tetrazólio. Revista Brasileira de Sementes, Brasília, v. 23, n. 1, p. 108-115, 2001.

GONDIM, A .W. A.; FERNADES, B. Probabilidade de chuvas para o município de Areia- PB. Agropecuária Técnica. Areia, v. 1, n. 1, p. 55-63. 1980.
GUERRA, M. E. C.; MEDEIROS FILHO, S.; GALHÃO, M. I. Morfologia de sementes, de plântulas e da germinação de Copaifera langsdorfii Desf. (Leguminosae - Caesalpinioideae). Cerne, Lavras, v. 12, n. 4, p. 322-328, 2006.

LORENZI, H.; BACHER, L.; LACERDA, M.; SARTORI, S. Frutas brasileiras e exóticas e cultivadas: (de consumo in natura). São Paulo: Instituto Plantarum de Estudos da Flora, 2006. 640 p.

MARCOS FILHO, J. Fisiologia de sementes de plantas cultivadas. Piracicaba: Fealq, 2005. 495 p.

MELO, M. F.; MACEDO, S. T.; DALY, D. C. Morfologia de frutos, sementes e plântulas de nove espécies de Protium Burm. f. (Burseraceae) da Amazônia Central, Brasil. Acta Botânica Brasílica, São Paulo, v. 21, n. 3, p. 503-520, 2007.

OLIVEIRA, E. C. Morfologia de plântulas florestais. In: AGUIAR, I. B.; PIÑA-RODRIGUES, F. C. M.; FIGLIOLIA, M. B. Sementes florestais tropicais. Brasília: ABRATES, 1993. p. 75-214. (Informativo ABRATES).

PINHEIRO, C. V. B. Germinação de sementes de palmeiras: revisão bibliográfica. Teresina: EMBRAPA/ UEPAE, 1986. $102 \mathrm{p}$.

QUEIROZ, M. S. M.; BIANCO, R. Morfologia e desenvolvimento germinativo de Oenocarpus bacaba Mart. (Arecaceae) da Amazônia Ocidental. Revista Árvore, Viçosa, v. 33, n. 6, p. 1037-1042, 2009.

RAMOS, M. B. P.; FERRAZ, I. D. K. Estudos morfológicos de frutos, sementes e plântulas de Enterolobium schomburgkii Benth. (Leguminosae Mimosoideae). Revista Brasileira de Botânica, São Paulo, v. 32, n. 2, p. 227-235, 2008.

RODERJAN, C. V. Morfologia do estádio juvenil de 24 espécies arbóreas de uma floresta com araucária. 1983. Dissertação (Mestrado em Engenharia Florestal) Universidade Federal do Paraná, Curitiba.

SILVA, K. B.; ALVES, E. U.; BRUNO, R. L. A.; MATOS, P. V.; GONÇALVES, E. P. Morfologia de frutos, sementes, plântula e plantas de Erytrhina velutina Willd. Leguminoseae - Papilionideae. Revista Brasileira de Sementes, Londrina, v. 30, n. 3, p. 104-114, 2008.

VIDAL, V. N. Considerações sobre as sâmaras que tem ala paranuclear. Rodriguésia, Rio de Janeiro, v. 30, n. 1, p. 109-168, 1978.

VIDAL, W. N.; VIDAL, M. R. R. Botânica: organografia. 4. ed. Viçosa: UFV, 2000. 114 p. 